\title{
Akdeniz meyve sineği Ceratitis capitata (Wiedemann) (Diptera: Tephritidae)'nın elma bahçelerinde popülasyon değişimleri üzerinde araştırmalar
}

\author{
Studies on population development of Mediterranean fruit fly Ceratitis capitata \\ (Wiedemann) (Diptera: Tephritidae) in apple orchards
}

\author{
Papatya TíFTíkCi(i) \\ T.C. Tarım ve Orman Bakanlığı, Çanakkale İl Müdürlüğü, 17100, Çanakkale \\ Sorumlu yazar (Corresponding author): P. Tiftikci, e-posta (e-mail): papatyademirezer@hotmail.com
}

\section{MAKALE BİLGİSİ}

Alınıș tarihi 10 Mart 2020

Düzeltilme tarihi 13 Mayıs 2020

Kabul tarihi 15 Mayıs 2020

\section{Anahtar Kelimeler:}

Akdeniz meyve sineği

Ceratitis capitata

Elma

Feromon

Popülasyon

\begin{abstract}
ÖZ
Ceratitis capitata (Wiedemann), bașta turunçgiller olmak üzere birçok meyve türünde öneml bir dış karantina zararlısıdır. Bu çalışma, 2016-2019 yılları arasında Çanakkale'de yürütülmüştür. Akdeniz meyve sineğinin popülasyon değişimlerini tespit etmek amacıyla elma bahçelerine Trimedlure içeren delta tipi feromon tuzaklar yerleştirilmiştir. Çalışma sonucunda, Akdeniz meyve sineğinin popülasyonunun 2016, 2018 ve 2019 yıllarında yüksek seviyelerde, 2017 yılında ise düşük değerlerde olduğu belirlenmiştir. Çalıșmada, Akdeniz meyve sineğinin 2016 yılında ekim-aralık aylarında, 2017 yılında kasım ayında, 2018 yılında ekim ve kasım aylarında, 2019 yılında ise eylül-aralık aylarında popülasyonu gözlenmiştir. Akdeniz meyve sineği, 10.10.2016 tarihinde tuzak başına 12 ergin, 14.11.2017 tarihinde tuzak başına 1 ergin, 31.10.2018 tarihinde tuzak başına 25 ergin, 21.11.2019 tarihinde ise tuzak başına 6 ergin ile tepe noktası oluşturmuştur.
\end{abstract}

ARTICLE INFO

Received 10 March 2020

Received in revised form 13 May 2020

Accepted 15 May 2020

\section{Keywords:}

Apple

Ceratitis capitata

Mediterranean fruit fly

Pheromone

Population

\begin{abstract}
Ceratitis capitata (Wiedemann) is an important external quarantine pest in many species of fruits, especially citrus. This study was carried out in Çanakkale between 2016-2019 years. In order to determine the population changes of the Mediterranean fruit fly, pheromone traps containing Trimedlure have been placed in the apple orchards. As a result of the study, it was determined that the population of the Mediterranean fruit fly was at high levels in 2016, 2018 and 2019, and low in 2017. In the study, the population of the Mediterranean fruit fly was observed in october-december in 2016, in november in 2017, in october-november in 2018 , and in september-december in 2019. The Mediterranean fruit fly has formed a peak with 12 adults per trap on $10.10 .2016,1$ adult per trap on $14.11 .2017,25$ adults per trap on 31.10 .2018 , and 6 adults per trap on 21.11.2019.
\end{abstract}

\section{Giriş}

Elma (Malus domestica L.) Rosaceae familyasina ait, çiçekleri yapraklarla birlikte açan bir meyve ağacıdır. Anavatanı Kuzey Anadolu, Kafkaslar, Rusya ve Orta Asya'dır. Türkiye, dünyada en fazla elma tüketen ülkeler arasındadır. Yıllık üretim ise 3.5 milyon ton'dur. Ülkemizde en fazla elma üreten il Isparta'dır (TÜİK 2019). Geniş alanlarda yetiştiriciliği yapılan, iç tüketim ve ihracatımız için önemli bir yere sahip olan elma ağaçlarında zarara sebep olan 39 zararlı tür bulunmaktadır (GTHB 2011). Bu zararlılar içerisinde Ceratitis capitata dış karantinaya tabi olması açısından önemlidir. Ceratitis capitata'nın ekonomik zararlı tür olmasında en büyük faktör polifag bir zararlı olmasıdır. Çanakkale'de yapılan çalışmada, yaz aylarında mandalina, şeftali, kayısı ve erikte yüksek popülasyon oluşturan C. capitata'nın, sonbaharda nektarin, elma, ayva ve armut bahçelerine geçtiği bildirilmiştir (Tiftikci 2017). Yunanistan'da yapılan çalışmada, C. capitata'nın haziran ve temmuz aylarında kayısı ve şeftalide, eylül ayında elma ve armutta, ağustos ayında kiraz ve erikte saptandığı belirtilmiştir (Papadopoulos ve ark. 2003). Zararlı, tropik ve subtropik bölgelerde büyük epidemiler oluşturmaktadır. Yapılan çalışmalarda zararlının ekonomik kayıplara sebep olduğu bildirilmiştir (Demirdere 1961; İleri 1961; Zümreoğlu 1979; Özkan 1993; Başpınar ve ark. 2009). Zararlı, Akdeniz'e kıyısı olan ülkelerde ekonomik zararlar meydana getirmektedir (Papadopoulos ve ark. 1998). Ülkemizde C. capitata ilk kez 1939 yılında Ankara'da şeftali ve kayısıda, 1958 yılında Kayseri'de armutta, 1960 yllinda ise Ankara'da armutta saptanmıştır (Bodenheimer 1951; İleri 1961). Çanakkale'de 
toplam 23 bin da alanda elma yetiştiriciliği yapılmaktadır (ÇKS 2019). Daha fazla ve kaliteli ürün elde etmek için elmada hastalık, zararlı ve yabancı otlarla mücadele önem arz etmektedir (GTHB 2011). Doğal ve doğal olmayan orman alanları, tarım alanları, meyve bahçeleri ve yerleşim alanlarında BioLure tuzakları ile yüksek yoğunlukta $C$. capitata yakalandığı, ancak bu tuzakların hedef dışı yararlı ve zararlı türleri de $\% 20$ oranında çektiği belirtilmiştir (Leblanc ve ark. 2010). Ceratitis capitata'nın popülasyon yoğunluğu parametrelerinin saptanmasının mücadelede başarı şansını arttırdığı önceki çalışmalarda ifade edilmiştir (Tiftikci 2017). $\mathrm{Bu}$ nedenlerden dolayı bu çalışmada, elmada $C$. capitata'nın popülasyon dalgalanmalarının belirlenmesi amaçlanmıştır.

\section{Materyal ve Yöntem}

Çalışma, 2016-2019 yılları arasında Çanakkale'de yürütülmüştür. Akdeniz meyve sineğinin elmada popülasyon dalgalanmalarını belirlemek amaciyla enlemi $40^{\circ} 05.114$, boylamı $26^{\circ} 24.610$ ve yükseklik değeri $38 \mathrm{~m}$ olan deneme parseline tuzaklar asılmıştır. Çalışmanın yürütüldügüü parselde, tuzak olarak delta tipi tuzaklar ve Trimedlure içeren feromon kapsülleri kullanılmıştır. Akdeniz meyve sineğinin popülasyon dalgalanmasının takibi için tuzaklar $10 \mathrm{da}$ elma bahçesinin orta kısmına zararlının yoğunluğuna göre dekara 1-5 adet tuzak olacak şekilde yerleştirilmiş̧ir. Denemenin gerçekleştirildiği Granny Smith çeşidi elma ağaçları 10 yaşında olup, sıra arası 3 $\mathrm{m}$ ve sira üzeri $1.5 \mathrm{~m}$ mesafededir. Haftalı kontroller esnasında, deneme parselinde bulunan tuzaklardaki Akdeniz meyve sineği erginleri sayılmış ve toplamı alınmıştır. Tuzaklarda haftalık olarak yakalanan toplam birey sayısı tuzak sayısına bölünerek ortalama tuzak başına ergin birey sayısı hesaplanmıştır. Delta tipi tuzaklar, ağaçların taçlanma yapıları dikkate alınarak ağaçların güney-doğu kısmına, hâkim rüzgâr yönünde yerden $1.5 \mathrm{~m}$ yükseklikte, taç iz düşümünün $1 / 4^{\prime}$ lük kısmına yerleştirilmiştir. Feromonlar 4 haftada bir yenileri ile değiştirilmiştir. Asılan tuzaklar ocak ayından başlayıp aralık ayının sonuna kadar her hafta kontrol edilmiştir. Ayrıca haftalık kontroller esnasında bahçeler rasgele çaprazlama dolaşılarak ağaç üzerindeki vuruklu meyveler kontrol edilmiş, mücadelesinde Deltamethrin veya Malathion tercih edilmiştir. Çalışmalar süresince iklim verileri Çanakkale Meteoroloji İstasyonu'ndan sağlanmıştır (Çizelge 1, 2 ve 3).

Çizelge 1. Çanakkale ili 2016, 2017, 2018 ve 2019 yıllarına ait ortalama sıcaklık değerleri.

Table 1. The average temperature values of Çanakkale province 2016, 2017, 2018 and 2019 years.

\begin{tabular}{|c|c|c|c|c|}
\hline \multirow[b]{2}{*}{ Aylar } & \multicolumn{4}{|c|}{ Ortalama Sicaklık $\left({ }^{\circ} \mathrm{C}\right)$} \\
\hline & 2016 & 2017 & 2018 & 2019 \\
\hline Ocak & 7 & 4 & 8 & 8 \\
\hline Şubat & 11 & 8 & 9 & 7 \\
\hline Mart & 11 & 11 & 12 & 11 \\
\hline Nisan & 16 & 13 & 16 & 13 \\
\hline Mayıs & 18 & 19 & 20 & 20 \\
\hline Haziran & 25 & 24 & 23 & 26 \\
\hline Temmuz & 27 & 27 & 27 & 27 \\
\hline Ağustos & 27 & 27 & 27 & 28 \\
\hline Eylül & 23 & 22 & 22 & 23 \\
\hline Ekim & 17 & 16 & 17 & 19 \\
\hline Kasim & 13 & 13 & 13 & 18 \\
\hline Aralık & 5 & 11 & 8 & 11 \\
\hline
\end{tabular}

Çizelge 2. Çanakkale ili 2016, 2017, 2018 ve 2019 yıllarına ait ortalama nem değerleri.

Table 2. The average moisture values of Çanakkale province 2016, 2017, 2018 and 2019 years.

\begin{tabular}{|c|c|c|c|c|}
\hline \multirow[b]{2}{*}{ Aylar } & \multicolumn{4}{|c|}{ Ortalama Nem (\%) } \\
\hline & 2016 & 2017 & 2018 & 2019 \\
\hline Ocak & 73 & 77 & 77 & 76 \\
\hline Şubat & 78 & 75 & 81 & 76 \\
\hline Mart & 74 & 74 & 77 & 69 \\
\hline Nisan & 68 & 64 & 68 & 69 \\
\hline Mayıs & 70 & 65 & 70 & 65 \\
\hline Haziran & 62 & 64 & 64 & 59 \\
\hline Temmuz & 55 & 56 & 60 & 52 \\
\hline Ağustos & 59 & 54 & 57 & 53 \\
\hline Eylül & 60 & 58 & 64 & 54 \\
\hline Ekim & 66 & 67 & 73 & 68 \\
\hline Kasım & 71 & 75 & 76 & 72 \\
\hline Aralık & 69 & 73 & 78 & 72 \\
\hline
\end{tabular}


Çizelge 3. Çanakkale ili 2016, 2017, 2018 ve 2019 yıllarına ait toplam yağış değerleri.

Table 3. The total rainfall values of Çanakkale province 2016, 2017, 2018 and 2019 years.

\begin{tabular}{|c|c|c|c|c|}
\hline \multirow[b]{2}{*}{ Aylar } & \multicolumn{4}{|c|}{ Toplam Yağış (mm) } \\
\hline & 2016 & 2017 & 2018 & 2019 \\
\hline Ocak & 110 & 156 & 87 & 94 \\
\hline Şubat & 89 & 56 & 132 & 69 \\
\hline Mart & 53 & 23 & 57 & 64 \\
\hline Nisan & 15 & 15 & 17 & 86 \\
\hline Mayıs & 27 & 20 & 32 & 5 \\
\hline Haziran & 40 & 35 & 19 & 57 \\
\hline Temmuz & 0 & 17 & 16 & 20 \\
\hline Ağustos & 0 & 0 & 0 & 11 \\
\hline Eylül & 2 & 10 & 72 & 1 \\
\hline Ekim & 9 & 49 & 33 & 35 \\
\hline Kasim & 209 & 118 & 93 & 19 \\
\hline Aralık & 17 & 146 & 98 & 32 \\
\hline
\end{tabular}

\section{Bulgular ve Tartışma}

Akdeniz meyve sineğinin popülasyon dalgalanmalarını belirlemek amacıyla 2016 yılında elma ağaçlarına asılan tuzaklarda ekim ayında tuzak başına ortalama 19 ergin $C$. capitata yakalanmıştır. Çalışma süresince en yüksek birey sayısı elma parselinde ekim ayında tuzak başına ortalama 19 ergin olmuştur. Ekim ayı ortalama sıcaklık değerleri $17^{\circ} \mathrm{C}$, ortalama nem \%66 ve yağış $9 \mathrm{~mm}$ 'dir. Son erginler ise aralık ayında tuzak başına ortalama 7 ergin olarak belirlenmiştir (Şekil 1). Aralık ayı ortalama sicaklık değerleri $5^{\circ} \mathrm{C}$, ortalama nem $\% 69$ ve yağış 17 mm'dir. Çalışmanın ikinci yılı olan 2017 yılında, elma ağaçlarına asılan tuzaklarda kasım ayında tuzak başına ortalama 1 ergin $C$. capitata yakalanmıştır. Çalışma süresince en yüksek birey sayısı elma parselinde kasım ayında tuzak başına ortalama 1ergin olmuştur. Son erginler ise kasım ayında tuzak başına ortalama 1ergin olarak belirlenmiştir (Şekil 2). Kasım ayı ortalama sıcaklık değerleri $13^{\circ} \mathrm{C}$, ortalama nem $\% 75$ ve yağış 118 mm'dir. Çalışmanın üçüncü yılı olan 2018 yılında, elma ağaçlarına asılan tuzaklarda ekim ayında tuzak başına ortalama 34 ergin $C$. capitata yakalanmıştır. Çalışma süresince en yüksek birey sayısı elma parselinde ekim ayında tuzak başına ortalama 34 ergin olmuştur. Ekim ayı ortalama sicaklık değerleri $17^{\circ} \mathrm{C}$, ortalama nem $\% 73$ ve yağış $33 \mathrm{~mm}$ 'dir. Son erginler ise kasım ayında tuzak başına ortalama 3 ergin olarak belirlenmiştir (Şekil 3). Kasım ayı ortalama sıcaklık değerleri $13^{\circ} \mathrm{C}$, ortalama nem \%76 ve yağış 93 mm'dir. Çalışmanın son y1lı olan 2019 yılında, elma ağaçlarına asılan tuzaklarda eylül ayında tuzak başına ortalama 1 ergin $C$. capitata yakalanmıştır. Eylül ayı ortalama sıcaklık değerleri $23^{\circ} \mathrm{C}$, ortalama nem $\% 54$ ve yağış $1 \mathrm{~mm}$ 'dir. Çalışma süresince en yüksek birey sayısı elma parselinde kasım ayında tuzak başına ortalama 9 ergin olmuştur. Kasım ayı ortalama sıcaklık değerleri $18^{\circ} \mathrm{C}$, ortalama nem \%72 ve yağış $19 \mathrm{~mm}$ 'dir. Son erginler ise aralık ayında tuzak başına ortalama 4 ergin olarak belirlenmiştir (Şekil 4). Aralık ayı ortalama sıcaklık değerleri $11^{\circ} \mathrm{C}$, ortalama nem $\% 72$ ve yağış $32 \mathrm{~mm}$ 'dir.

Akdeniz meyve sineği, 2016 yılında ilk olarak ekim ayının ilk haftası tuzaklarda ortalama 1 ergin olarak saptanmıştır. Bir sonraki hafta popülasyon artmıştır. Ekim ayının ikinci haftasında en yüksek değer olan tuzak başına ortalama 12 ergin tespit edilmiştir. Birey sayısı sonraki haftalarda azalmıştır. Tuzaklarda yakalanan son sinekler ortalama 1 ergin olarak aralık ayının üçüncü haftasında kaydedilmiştir. Akdeniz meyve sineği 2017 yılında, kasım ayının ikinci haftası tuzaklarda ortalama 1 ergin olarak saptanmıștır. Akdeniz meyve sineği 2018 yılında, ekim ayının ilk haftası tuzaklarda ortalama 2 ergin olarak saptanmıştır. Sonraki haftalarda popülasyon sabit değerlerde değişim göstermiştir. Ekim ayının son haftasında en yüksek değer olan tuzak başına ortalama 25 ergin tespit edilmiştir. Birey sayısı bir sonraki hafta azalmıştır. Tuzaklarda yakalanan son sinekler ortalama 3 ergin olarak kasım ayının ilk haftasında belirlenmiştir. Akdeniz meyve sineği 2019 yılında, eylül ayının ilk haftası tuzaklarda ortalama 1 ergin olarak saptanmıştır. Sonraki haftalarda popülasyon artan ve azalan değerlerde değişim göstermiştir. Kasım ayının üçüncü haftasında en yüksek değer olan tuzak başına ortalama 6 ergin tespit edilmiştir. Tuzaklarda yakalanan son sinekler ortalama 1 ergin olarak aralık ayının ikinci haftasında kaydedilmiştir.

\section{Sonuç}

Çanakkale'de elma ağaçlarında 2016-2019 yıllarında Akdeniz meyve sineğinin popülasyon dalgalanmalarını belirlemek amacıyla yürütülen çalışmanın sonuçlarına göre, 2016, 2018 ve 2019 y1llarında popülasyon yoğunluğu yüksek, 2017 yılında ise popülasyon yoğunluğu düşük değerlerde saptanmıştır. Çalışmaların birinci yılında, Akdeniz meyve sineği ekim ayında popülasyon oluşturmaya başlamış, aralık ayının sonuna kadar popülasyonu gözlenmiştir. İkinci yıl çalışmalarında, Akdeniz meyve sineği kasım ayında popülasyon oluşturmuştur. Üçüncü yıl çalışmalarında, ekim ayında popülasyon oluşturmaya başlamış, kasım ayının ilk haftasına kadar popülasyonu gözlenmiştir. Çalışmaların dördüncü yılında, Akdeniz meyve sineği eylül ayında popülasyon oluşturmaya başlamış, aralık ayının ikinci haftasına kadar popülasyonu gözlenmiştir. Tuzaklarda yakalanan toplam birey sayısı 2016 yılinda ortalama 27 birey, 2017 y1linda ortalama 1 birey, 2018 yılında ortalama 37 birey, 2019 yllinda ortalama 16 birey olmuştur. Akdeniz meyve sineği feromon tuzaklarda yüksek seviyelere ulaşmasına karşın ağaçlarda yapılan kontrollerde vuruklu meyveye rastlanılmamıştır. 


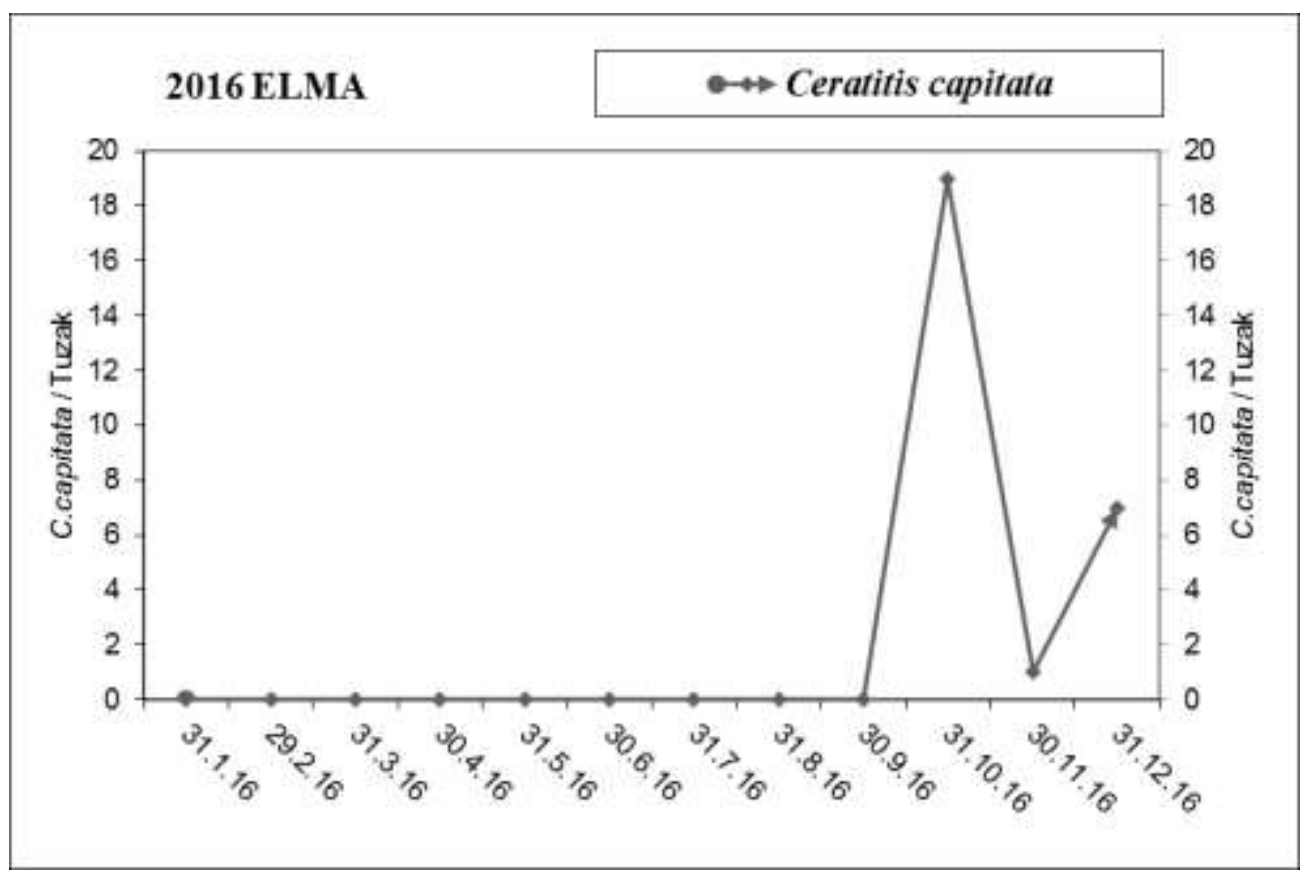

Şekil 1. Çanakkale'de elmada 2016 yılında C. capitata'nın popülasyon dalgalanmaları.

Figure 1. The population development of $C$. capitata in 2016 year in the apple.

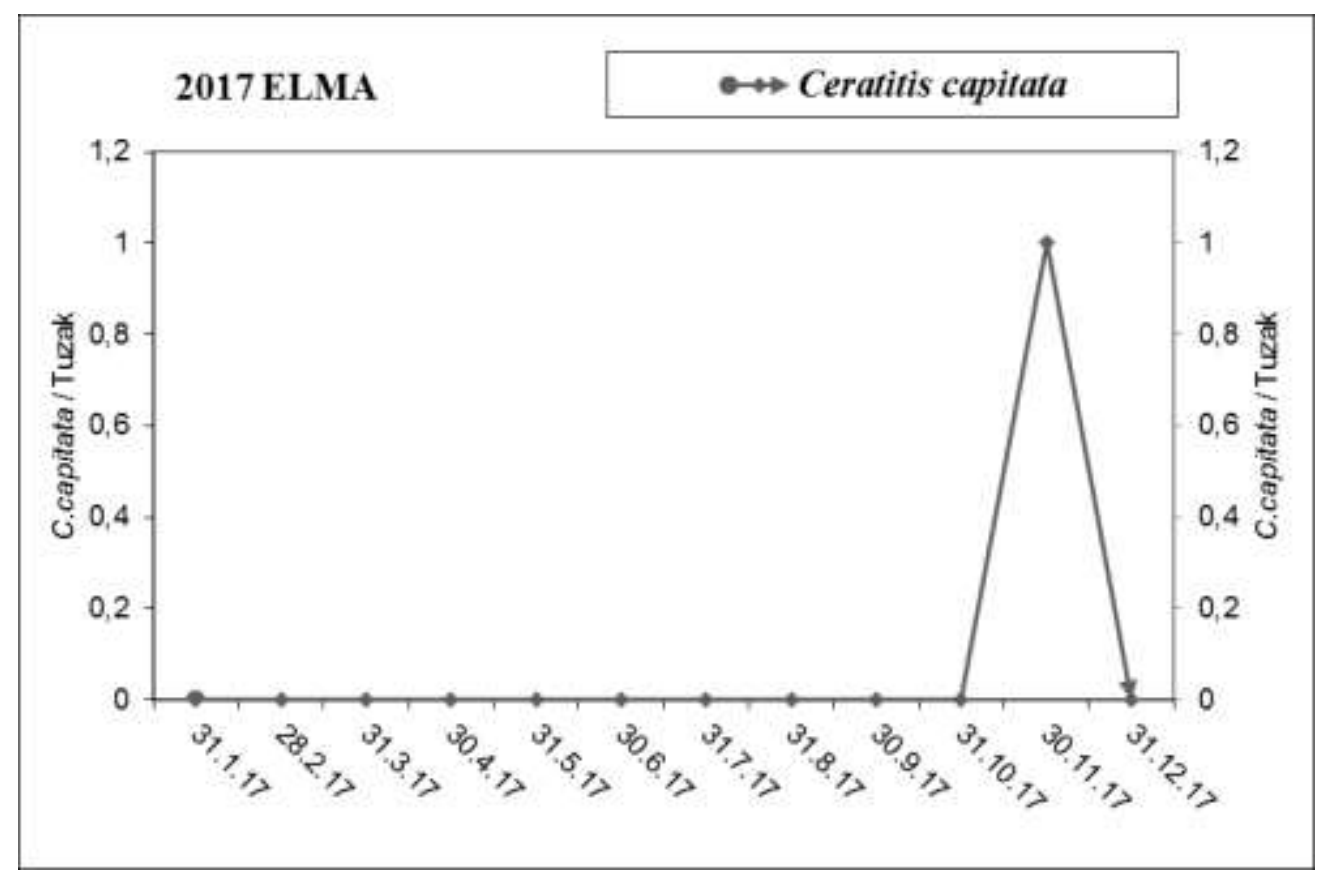

Şekil 2. Çanakkale'de elmada 2017 yılında C. capitata'nın popülasyon dalgalanmaları.

Figure 2. The population development of $C$. capitata in 2017 year in the apple. 


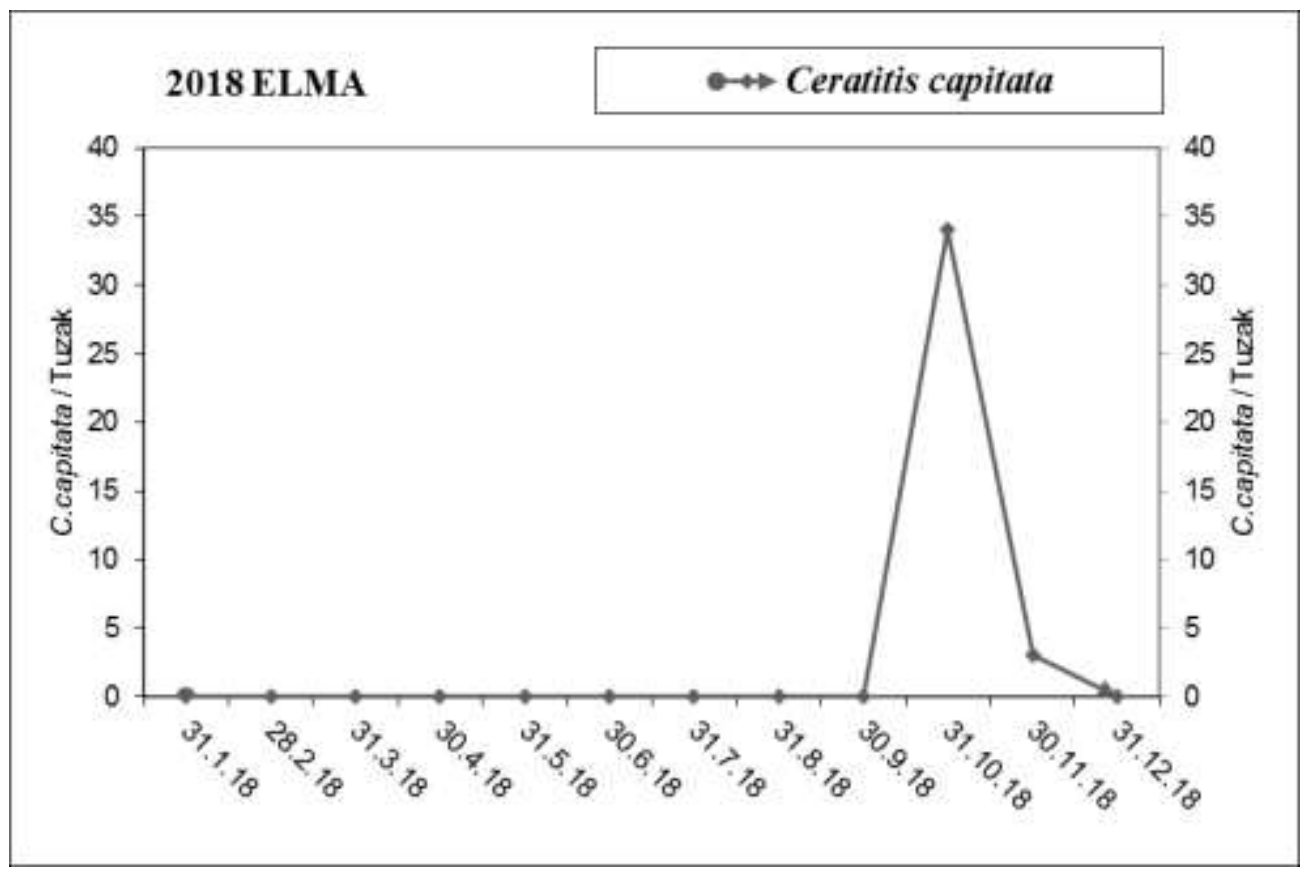

Şekil 3. Çanakkale'de elmada 2018 yılında C. capitata'nın popülasyon dalgalanmaları.

Figure 3. The population development of $C$. capitata in 2018 year in the apple.

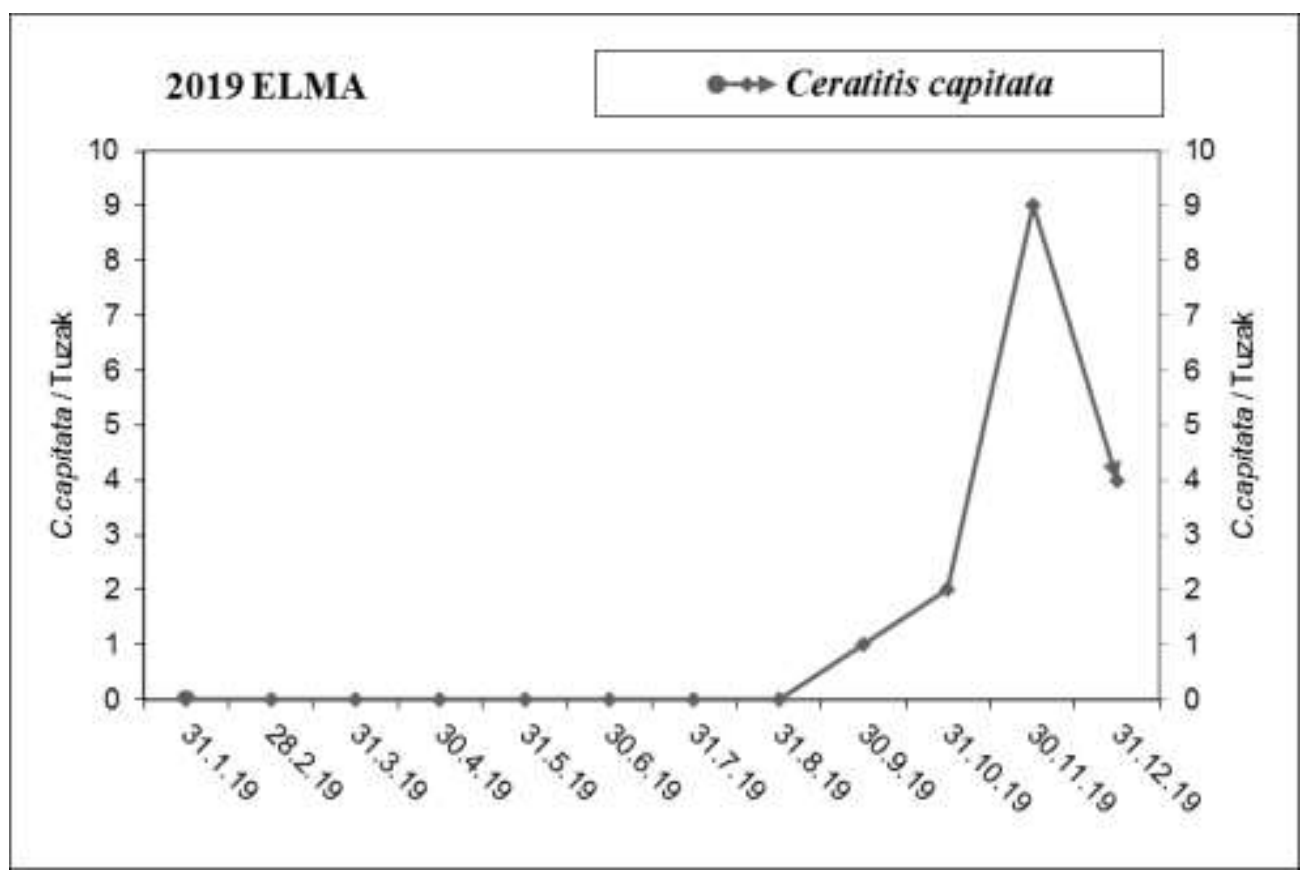

Şekil 4. Çanakkale'de elmada 2019 yılında C. capitata'nın popülasyon dalgalanmaları.

Figure 4. The population development of $C$. capitata in 2019 year in the apple.

\section{Teşekkür}

Feromon tuzakları temin eden Adana Biyolojik Mücadele Araştırma Enstitüsü'ne teşekkür ederim.

\section{Kaynaklar}

Başpınar H, Çakmak İ, Koçlu T, Başpınar N (2009) Aydın ili meyve bahçelerinde Akdeniz meyve sineği Ceratitis capitata (Wiedemann) (Diptera: Tephritidae)'nin biyo-ekolojisi, zararı, yayılışı ve turunçgil bahçeleri üzerindeki çalışmaları. Türkiye II. Bitki Koruma Kongresi Bildirileri, Isparta, s. 48.

Bodenheimer FS (1951) Citrus entomology in the Middle East. Den Haag.

ÇKS (2019) İl Müdürlüğü Çiftçi Kayıt Sistemi verileri, Çanakkale.

Demirdere A (1961) Cukurova Bölgesinde Akdeniz meyve sineği (Ceratitis capitata Wied.)'nin biyolojisi ve mücadelesi üzerinde çalışmalar. Zirai Mücadele ve Zirai Karantina Müdürlüğü, Ankara, s. 118. 
GTHB (2011) Elma entegre mücadele teknik talimatı. Gıda, Tarım ve Hayvancılık Bakanlığı, Ankara.

İleri M (1961) Türkiye'de Akdeniz meyve sineği (Ceratitis capitata Wied.) durumu ve mücadelesi. Tarım Bakanlığı, Zirai Mücadele Araştırma Enstitüsü, Ankara, s. 38.

Leblanc L, Vargas RI, Rubinoff D (2010) Captures of pest fruit flies (Diptera: Tephritidae) and non-target insects in biolure and torula yeast traps in Hawaii. Environmental Entomology 32: 1626-1630.

Özkan C (1993) Doğu Akdeniz Bölgesi'nde Akdeniz meyve sineği, Ceratitis capitata (Wiedemann) (Diptera: Tephritidae)'nın konukçu değișimi üzerinde araștırmalar. Çukurova Üniversitesi, Fen Bilimleri Enstitüsü, Bitki Koruma Anabilim Dalı, Yüksek Lisans Tezi, Adana, s. 54.

Papadopoulos NT, Katsoyannos BI, Carey JR (1998) Temporal changes in the composition of the overwintering larval population of the
Mediterranean fruit flies (Dipt.,Tephritidae) in Northern Greece. Entomological Society of America 91(4): 430-434.

Papadopoulos NT, Katsoyannos BI, Nestle D (2003) Spatial autocorrelation analysis of a Ceratitis capitata (Diptera: Tephritidae) adult population in a mixed deciduous fruit orchard in Northern Greece. Environmental Entomology 32(2): 319-326.

Tiftikci P (2017) Çanakkale'de Akdeniz meyve sineği Ceratitis capitata Wiedemann (Diptera: Tephritidae)'nın genel durumunun değerlendirilmesi. II. Çanakkale Tarımı Sempozyumu Bildirileri, Çanakkale, s. 108.

TÜİK (2019) Türkiye İstatistik Kurumu verileri, Ankara.

Zümreoğlu A (1979) Sterile-Male tekniğini mücadelede uygulamak gayesiyle suni ortamlarda Akdeniz meyve sineği Ceratitis capitata Wied. (Diptera: Tephritidae)'nın yetiştirme metotları üzerinde araştırmalar. Zirai Mücadele Müdürlüğü, Ankara, s. 84. 